\title{
Flight Evaluation of Helicopter Curved Point-in-Space Approach Procedures
}

\author{
Omkar Halbe* and Mario Hamers $\ddagger$ \\ Airbus Helicopters Deutschland GmbH, 86609 Donauwörth, Germany \\ and \\ Thomas Lüken $¥$ and Sven Schmerwitz \\ German Aerospace Center (DLR), 38108 Braunschweig, Germany
}

\begin{abstract}
https://doi.org/10.2514/1.D0210
Helicopter point-in-space instrument procedures are key to enabling simultaneous noninterfering procedures and enhancing all-weather access in dense airspace and remote locations. This paper describes the flight evaluation of navigation and human performance in helicopter curved point-in-space procedures as part of Single European Sky Air Traffic Management Research. An experimental procedure was designed at Donauwörth heliport including radius-to-fix legs with descent gradients and airspeed variations in the terminal segments, followed by a steep, straight-in final approach segment. Two strategies were evaluated for vertical descent profiles: fixed flight path angle, and fixed vertical speed. Three test pilots were instructed to execute the entire approach until the missed approach point in simulated instrument meteorological conditions using advanced autopilot modes and head-down flight and navigation displays. Navigation performance was measured using cross-track and vertical-track deviations. Pilot workload and situational awareness were measured using the task load index and the situational awareness rating technique, respectively. The results showed that flight paths were maintained within the required navigation performance limits despite strong crosswinds, and the final approach glidepath was successfully captured in all cases. All pilots reported low workload, adequate spare capacity, and high situational awareness in all cases. Furthermore, the fixed flight path angle descent was found to induce lower workload and required fewer crew actions compared with the fixed vertical speed descent. Owing to the small sample size, conclusions with statistical significance cannot be established.
\end{abstract}

\section{Introduction}

$\mathbf{H}$ ELICOPTERS have been in operation for many decades, and yet helicopter operations are not yet fully integrated into the air traffic management (ATM) network. Many helicopter operations continue to be performed under visual flight rules (VFR) in visual meteorological conditions (VMC). Vital missions such as helicopter emergency medical services too are mostly performed under VFR in clear day/night and at times even in lower visibility conditions with special approvals from local authorities. Whereas VFR/VMC limit helicopter availability for critical missions, flying in low visibility conditions imposes significant risks on overall flight safety. Studies that have analyzed past helicopter accident records identify numerous causal factors and risks [1, 2] ]. Of those factors, pilot judgment and actions were leading causes of all accidents. Of the identified risks, inadvertent entry in instrument meteorological conditions (IMC) and controlled flight into terrain (CFIT) have catastrophic consequences. There is also evidence to suggest that helicopter pilot performance drops significantly upon encountering inadvertent IMC [3]. Many of today's commercial helicopters are certified for instrument flight rules (IFR) and offer advanced onboard avionics and flight automation. It is therefore essential that IFR procedures are adopted not only to enhance the safety of helicopters, but also to enable their seamless integration into the current and future ATM framework.

The transition from conventional ground navigation aids to a system based on the Global Navigation Satellite System (GNSS) has renewed interest in IFR procedures for helicopter operations. GNSS provides a ubiquitous, reliable, and accurate means of navigation, thus making it

Received 13 April 2020; revision received 2 October 2020; accepted for publication 21 October 2020; published online Open Access 18 December 2020. Copyright $\odot 2020$ by Airbus Helicopters Deutschland GmbH. Published by the American Institute of Aeronautics and Astronautics, Inc., with permission. All requests for copying and permission to reprint should be submitted to $\mathrm{CCC}$ at www.copyright.com; employ the eISSN 2380-9450 to initiate your request. See also AIAA Rights and Permissions www.aiaa.org/randp.

*Systems Engineer and Air Traffic Management Expert.

${ }^{\dagger}$ Lead Flight Test Engineer.

†Project Manager and Researcher, Institute of Flight Guidance. an ideal enabler of helicopter IFR procedures. The performance of GNSS has been further enhanced by satellite-based augmentation system (SBAS), such as European Geostationary Navigation Overlay Service (EGNOS) in Europe and Wide Area Augmentation System (WAAS) in the United States, and has led to more accurate onboard navigation capabilities. Furthermore, new guidelines for the design and construction of IFR procedures define dedicated GNSS-based helicopter approach and departure procedures to specified points in space (PinS) [4]. Such PinS can be placed in close proximity to, but not necessarily aligned with, a runway, a helipad, or an intended landing spot. In such approaches, it is sufficient that the pilot acquires visual references associated with the landing spot before proceeding to land using visual references [4]. Thus, a combination of GNSS-based navigation and advances in procedure design can support operations tailored to the unique flight capabilities of helicopters, moving closer toward full integration of helicopters into the future ATM framework.

The objective of the Single European Sky ATM Research (SESAR) is to develop a safe, efficient, and intelligent air traffic system that integrates all airspace users by leveraging the latest technological advancements. A previous SESAR rotorcraft project evaluated the feasibility of dedicated low-level IFR routes and PinS approaches with straight legs. It advocated automation and enhanced vision systems to ensure maximum compliance to the required navigation performance (RNP) [5]. The present research project within the SESAR 2020 framework investigated the concept of helicopter curved PinS procedures, including radius-to-fix (RF) flight legs with descent gradients in the approach, departure, and missed approach segments. The project objective was to demonstrate readiness for operational deployment of curved PinS procedures that are expected to reduce helicopters' dependence on weather conditions, to improve helicopter accessibility to remote areas, and to ease helicopter integration into busy airspace without interfering with fixed-wing operations. The latter point is also known as the simultaneous noninterfering (SNI) concept, which has shown promise for strategic decongestion of dense airspace [6] and alleviation of community noise impact [7]. Previous studies into helicopter IFR procedures investigated the feasibility of SBASenabled IFR steep approaches [으뭉, IFR noise abatement procedures [11], and novel guidance display concepts [12]. A more recent study 
demonstrated navigation performance and contingency procedures in low-level helicopter IFR routes and RNP approach (APCH) with authorization required (AR) in mountainous terrain [13]. Likewise, recent works on curved approaches for fixed-wing aircraft evaluated the potential fuel and emission benefits [14] as well as the navigation performance for general and business aviation through flight testing [15]. This paper describes the development, flight demonstration, and performance evaluation of curved PinS helicopter procedures using advanced onboard avionics functions in representative and realistic test conditions. It is not the intention of the paper to provide statistically significant results; rather, the results of the flight testing will be discussed in a qualitative sense.

The remainder of the paper is organized as follows: Section II gives a brief overview of the curved PinS concept. Section III defines the research objectives of the present work. Section IV describes the experimental setup, including procedure design, test platform description, and data collection techniques for the flight trials. Section $\mathrm{V}$ presents the navigation and human performance results of the flight trials. Section VI discusses the results in the context of the main SESAR objectives. Finally, Sec. VII summarizes the outcomes of this work.

\section{Brief Overview of the Radius-to-Fix and Point-in-Space Concepts}

SBAS-guided PinS procedures are designed to simplify helicopter operations and ease accessibility, in particular in adverse weather conditions, because the existence of VMC is required only between the PinS and the landing location. Although PinS procedures can be developed almost everywhere, the principal interest lies both in dense airspace and at landing locations that do not possess adequate properties for an IFR heliport in accordance with the regulations [16]. Furthermore, PinS approaches and departures can be connected to a low-level helicopter IFR route network for point-to-point connectivity, as demonstrated in [13]. By giving the procedure designer flexibility in the placement of the specified points in space, PinS procedures can unlock access from multiple approach directions, regardless of the orientation of the runway. Curved PinS that include $\mathrm{RF}$ legs in the terminal segments except the final approach segment are also referred to as advanced PinS in the SESAR 2020 framework. In terms of benefits, RF legs avoid overshoots at waypoint transitions where large course changes are required. In fact, experimental studies have shown that flight technical error in RF legs is remarkably low and well within the RNP limits despite different aircraft types, different flight management system (FMS) manufacturers and varying wind conditions [17]. Furthermore, RF legs simplify the task of avoiding noise-sensitive and obstacle-rich areas without significantly increasing the along-track distance. Although there has been some work on exploiting the capabilities of RF legs in constructing terminal procedures $[\underline{18}, \underline{19}]$ as well as the use of the point merge concept using quasi arcs [20], no study exists that is specifically aimed at rotorcraft operations. Furthermore, the provision of altitude variations, such as step-down fixes or a continuous descent gradient in the terminal approach segments, can ease access to difficult terrain and help the pilot prepare for the final glidepath capture. Altitude variations may also be an operational necessity in high-density terminal maneuvering areas for maintaining adequate vertical separation, or to ensure terrain clearance in mountainous areas.

The PinS final approach (RNP APCH) is typically published with either localizer performance with vertical (LPV) guidance minima (three-dimensional [3-D] guidance) or lateral navigation (LNAV) minima (two-dimensional guidance) [4]. The last point in PinS is also the missed approach point (MAPt). Upon reaching the PinS/ MAPt, the pilot has to acquire visual references associated with the heliport or the intended landing location. From the PinS/MAPt, the pilot follows either a "proceed visually" or a "proceed VFR" instruction to land on the designated spot. Proceed visually provides obstacle protection in the visual segment. However, proceed VFR requires an IFR/VFR transition and offers no obstacle protection in the visual segment. The pilot is then required to see and avoid obstacles. If visual references cannot be acquired at the PinS/MAPt, then the pilot must execute a missed approach. A typical curved PinS approach procedure in mountainous terrain is illustrated in Fig. 1. It shows two terminal segments, namely, initial approach and intermediate approach, followed by the final approach until the PinS/ MAPt. A visual segment extends between the PinS/MAPt and the helipad, and a missed approach segment extends between the PinS/ MAPt and the missed approach holding fix (MAHF).

Not only do advanced PinS procedures enhance the operational envelope with regard to weather and location, but they also adequately address the helicopter's unique flight characteristics in terms of airspeed limit down to $70 \mathrm{kts}$, smaller turn radii of curves, and steeper climb and descent gradients. For executing PinS procedures, appropriate lateral and vertical guidance commands are issued by the FMS. The guidance commands are then executed automatically by an autopilot using appropriate roll steering commands. Thus, continuous monitoring and closure of the cross-track and verticaltrack errors improve path predictability and lead to safer operations.

\section{Research Objectives}

Helicopters form a small but important component of low-level airspace traffic. On the one hand, the coexistence of helicopters with airline traffic in dense airspace is a point of concern for air traffic controllers (ATC). On the other hand, helicopters operating in uncontrolled airspace must manage unforeseen weather conditions, difficult terrain, potentially unknown obstacles, and proximity to other VFR traffic with no ATC oversight. To address these challenges, the present work was aimed at assessing the potential safety improvements and the maturity of advanced PinS for operational use.

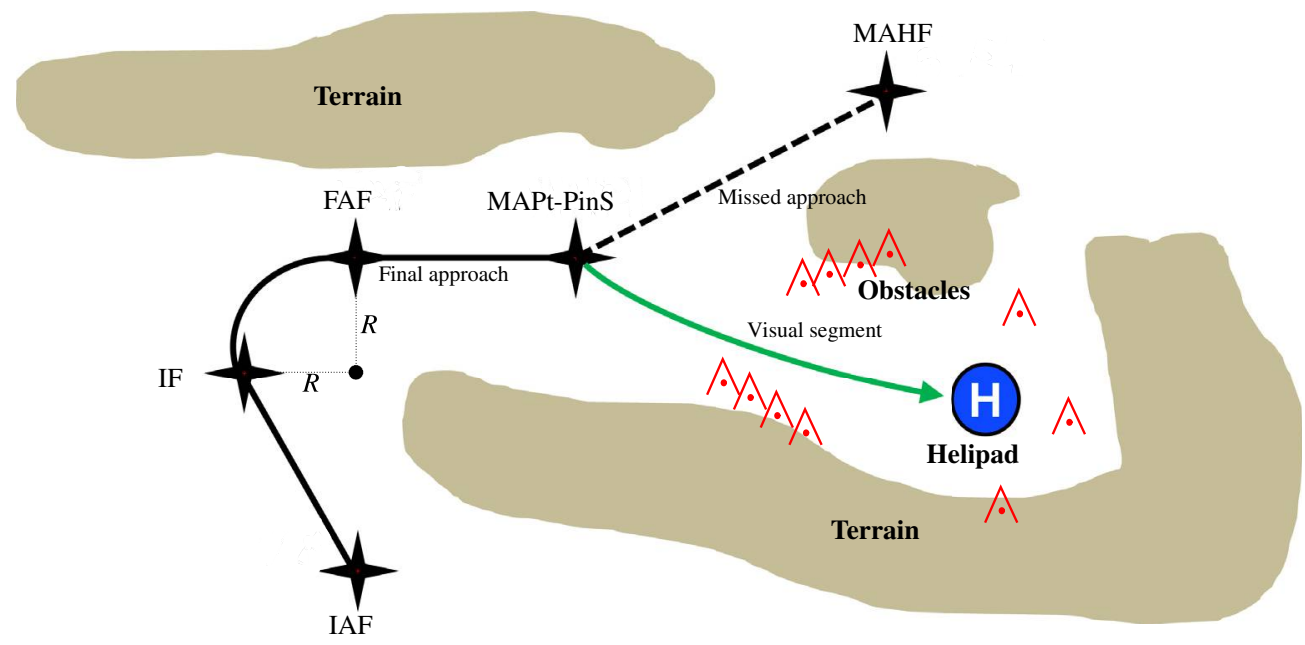

Fig. 1 A typical PinS approach with RF leg in the intermediate segment. 
The validation exercises included flight testing of an advanced PinS procedure and covered the following activities:

1) The first objective was to generate evidence regarding navigation performance to verify RNP specification.

2) The second objective was to generate evidence regarding human performance in terms of pilot workload and pilot situational awareness.

3) The third objective was to evaluate the benefit of an integrated modular avionics suite and advanced autopilot modes to automate the execution of advanced PinS procedures.

4) The fourth objective was to assess the impact of helicopters on capacity, efficiency, safety, predictability, equity, and access to the future ATM network.

Flight tests were conducted using an IFR-certified helicopter in representative environmental conditions at the Airbus Helicopters plant in Donauwörth, Germany, jointly with German Aerospace Center (DLR) research facility in Braunschweig, Germany, and under contract from the SESAR Joint Undertaking. To the best knowledge of the authors, this is the first study reporting on navigation and human performance for advanced helicopter IFR procedures.

\section{Experimental Setup}

Donauwörth (International Civil Aviation Organization [ICAO] code: EDPR) is located in uncontrolled class $\mathrm{G}$ airspace from ground to $1000 \mathrm{ft}$ above ground level (AGL) as shown in Fig. 2. Airspace class $\mathrm{G}$ offers no ATC oversight in terms of VFR and IFR separations and radar surveillance. However, Airbus operates an information and weather service on dedicated frequencies. A radio mandatory zone (RMZ) has been established around EDPR as seen in Fig. 2. Also shown in the same figure, airspace class E extends from $1000 \mathrm{ft}$ AGL to flight level (FL) 100, in which VFR to IFR separations are not offered but traffic information is provided as far as is practicable. The EDPR environment offers flight in low-density, uncontrolled airspace with potential VFR traffic in the IFR segments and obstacles avoidance in the visual segments. To extend the experimental results to high-density airspace, it will be assumed that the navigation and human performance during PinS execution in other airspace classes is comparable, and that workload due to air traffic control interactions is not substantially higher than navigation and surveillance tasks.

\section{A. Advanced Point-in-Space Procedure Construction}

EDPR is an instrument heliport in accordance with ICAO Annex 14 [16]. An experimental advanced PinS to EDPR heliport was constructed in accordance with the procedure construction criteria [4] and RNP specification [21]. As shown in Fig. 3, it consists of three RF legs in the intermediate approach segment between waypoints PRYKO and FROGS. The radius of each RF leg was determined from guidance material on turn area construction [4]. Using a maximum true airspeed of $100 \mathrm{kts}$, a maximum wind speed of $30 \mathrm{kts}$, a maximum turn rate of $3^{\circ} / \mathrm{s}$, and a maximum bank angle of $20^{\circ}$, a turn radius of $0.7 \mathrm{n}$ mile was computed. The three consecutive RF legs require successive reversals in turn direction along the approach. The third RF leg

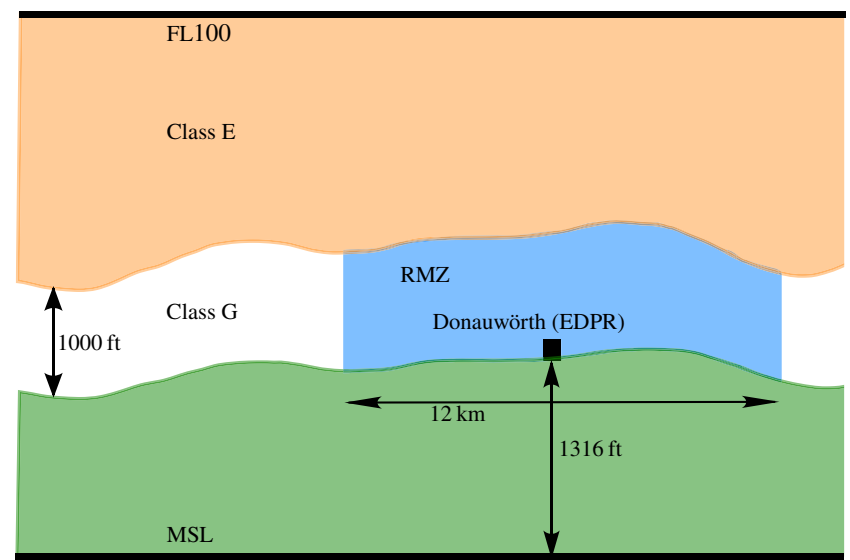

Fig. 2 Low-level airspace structure around Donauwörth.
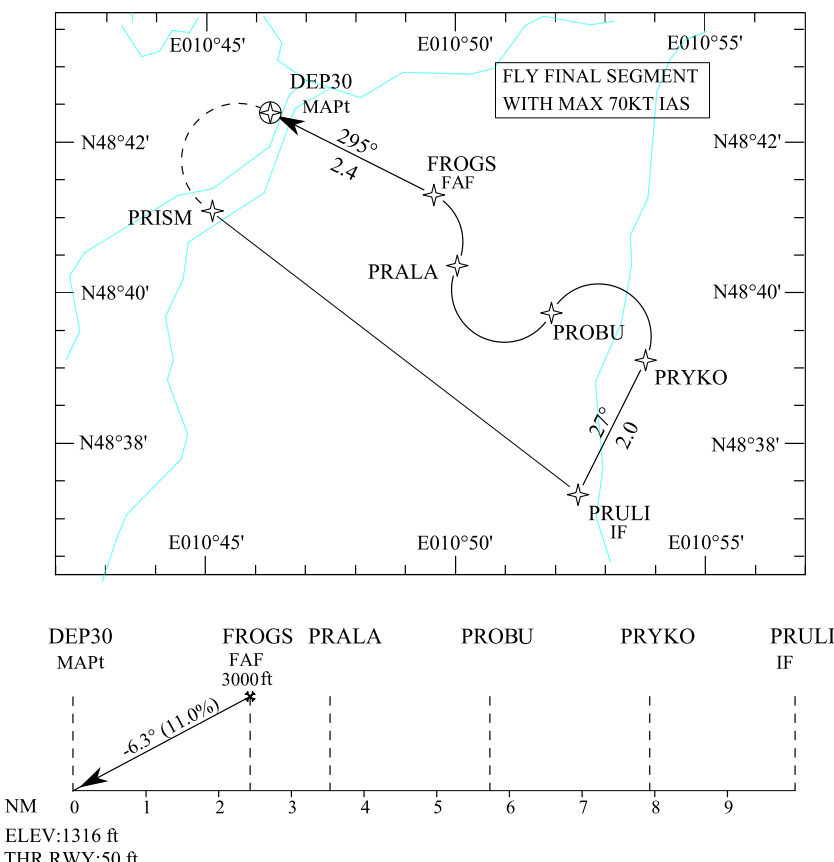

Fig. 3 Horizontal and vertical views of the advanced PinS approach procedure to Donauwörth heliport.

terminates directly at the final approach fix (FROGS). However, the flight path between waypoints PRALA and FROGS requires a $90^{\circ}$ track angle change, whereas a maximum of $60^{\circ}$ is prescribed in the guidance material. It is required to achieve RNP 0.3 in these terminal phases of the approach. Thereafter, the final approach segment (FAS) has a steep glidepath of $6.30^{\circ}$, which is the maximum permissible glidepath for helicopters in the guidance material. The FAS is designed in accordance with RNP APCH specification [21]. The FAS is limited to $70 \mathrm{kts}$ airspeed and is flown down to LPV minima of $350 \mathrm{ft}$ decision height until the MAPt. The missed approach also consists of an RF leg of radius $0.7 \mathrm{n}$ mile until the initial approach fix (PRISM). The initial approach segment terminating at PRULI, which is the intermediate fix (IF), and the first leg of the intermediate approach segment terminating at PRYKO constitute track to fix (TF) legs. Table 1 lists the waypoint coordinates, the type of path terminators, and the centers of those identified as RF legs.

Figure 4 shows a 3-D view of the approach procedure along with populated areas. The three RF legs in the intermediate approach segment were placed in a manner that results in the aircraft flying around, instead of over these populated areas. The final approach is aligned with the desired track at landing and passes between populated areas on either side of the approach track. The absence of a straight segment $2 \mathrm{n}$ mile before the final approach fix makes the scenario challenging for RNP APCH final approach guidance due to the reduced scaling transition from terminal mode to approach mode. In practice, a true PinS procedure may not deliver a helicopter in the proximity of and aligned with the desired final track angle. However, the present flight tests were primarily focused on the curved segments and the ability to capture the glidepath. The transition from IFR to VFR at or before the MAPt was beyond the scope of this work.

\section{B. Vertical Profiles in Terminal Phase}

The intermediate approach segment begins at PRULI and ends at the final approach fix FROGS. Two different vertical profiles were investigated in the intermediate approach segment: constant altitude and variable altitude. Whereas the former relies on lateral navigation with appropriate altitude hold modes, the latter requires both LNAV and vertical navigation (VNAV) capability. For the variable altitude terminal phase, two candidate strategies were investigated: fixed flight path angle (FPA) descent, and fixed vertical speed (VS) descent. In all, three cases relating to the different approach profiles were evaluated. 
Table 1 Waypoints in the EDPR advanced PinS approach procedure

\begin{tabular}{lccc}
\hline \hline Waypoint name & Geographic coordinates & Path terminator & Leg center \\
\hline PRULI & N 48.622186 E 10.874286 & IF & -- \\
PRYKO & N 48.651944 E 10.896861 & TF & - \\
PROBU & N 48.662422 E 10.865422 & RF & N 48.657183 E 10.881142 \\
PRALA & N 48.672900 E 10.833975 & RF & N 48.667661 E 10.849700 \\
FROGS & N 48.688556 E 10.826158 & RF & N 48.678142 E 10.818247 \\
DEP30 (MAPt) & N 48.706744 E 10.771478 & TF/LPV & N 48.696239 E 10.760714 \\
PRISM & N 48.684992 E 10.752169 & RF & E \\
\hline \hline
\end{tabular}

Case 1 refers to an intermediate approach segment at constant altitude of $3000 \mathrm{ft}$, followed by a $6.3^{\circ}$ final glidepath angle. Case 2 refers to a fixed FPA descent in which the nominal FAS glidepath angle of $6.3^{\circ}$ was extrapolated along the desired track for computing reference waypoint altitudes along the three RF legs. Case 3 refers to a fixed VS descent in which the nominal FAS vertical speed of $800 \mathrm{ft} / \mathrm{min}$ was to be followed along the three RF legs. For case 3, reference waypoint altitudes for a fixed VS were computed using reference waypoint airspeeds and assuming still air.

Table 2 presents a list of attributes of the terminal waypoints, and the airspeeds and altitudes applicable in each of the cases to be flight tested. The airspeed variations and the descent gradients in the advanced PinS procedure make it a quasi-four-dimensional approach.

\section{Test Platform Description}

The aircraft used in the flight trials were an experimental Airbus H145 prototype and an experimental Airbus H135 prototype, both holding European Union Aviation Safety Agency (EASA) civil-type certificates $[22,23]$. A representative image of the H135 is shown in Fig. 5a. Both helicopters are certified for VFR day/night and IFR (Category A) operations, and are widely deployed in a variety of missions, including emergency medical services, police and parapublic missions, and passenger transport. The cockpit layout with avionics equipment is shown in Fig. $5 \mathrm{~b}$. It provides seats for the pilot in command (PIC) on the right-hand side and the safety pilot or the flight test engineer (FTE) on the left-hand side. The HELIONIX avionics suite is installed in the latest generation of both aircraft. HELIONIX is designed using an integrated modular avionics concept. Nonexhaustive but key functional features of HELIONIX are 1) dual duplex four-axis autopilot, 2) intelligent flight and vehicle monitoring functions, 3) dual GNSS and flight management system (FMS) including automatic reconfiguration, and 4) external situational awareness using digital moving map (DMAP), helicopter terrain avoidance and warning system (HTAWS), synthetic vision system (SVS), and traffic advisory system (TAS).

These functions together are intended to enhance internal and external pilot situational awareness and reduce pilot workload in all
Table 2 Altitude and airspeed variations in EDPR advanced PinS approach procedure

\begin{tabular}{lcccc}
\hline \hline & & \multicolumn{3}{c}{ Altitude MSL (ft) } \\
\cline { 3 - 5 } Waypoint name & IAS (kts), all cases & Case 1 & Case 2 & Case 3 \\
\hline PRULI & 100 & 3000 & 6400 & 5700 \\
PRYKO & 100 & 3000 & 6400 & 5700 \\
PROBU & 90 & 3000 & 5000 & 4700 \\
PRALA & 80 & 3000 & 3600 & 3600 \\
FROGS & 70 & 3000 & 3000 & 3000 \\
DEP30 & 70 & 1666 & 1666 & 1666 \\
PRISM & 70 & 3000 & 3000 & 3000 \\
\hline \hline
\end{tabular}

phases of flight. All functions are integrated in an intuitive, humancentric cockpit display and control concept, which further contributes to the ease of piloting in both IFR and VFR. Detailed descriptions of the avionics functions supporting IFR procedures, namely, positioning, navigation, guidance, and automatic flight control, are available in [8]. Further details on the functional features of HELIONIX and how these contribute to crew situational awareness are found in [24].

Figure 6 shows the display symbology presented to the flight crew on the HELIONIX multifunctional displays (MFD). Figure 6a depicts the primary flight and navigation display format that is displayed to the PIC at all times. It includes a synthetic vision display including obstacles, terrain, ground vector indication, heliport identifier, and helipad display in the background and key primary information including speed, power, and attitude indicators in the foreground. Figure $6 \mathrm{a}$ also shows information presented during IFR approaches, including the horizontal and vertical deviations, desired track, level of service, and next waypoint data on the lower half of the display. The top row presents labels indicating the autopilot coupling statuses in the different axes. Figure $\underline{6 b}$ shows the navigation display format depicted on a separate MFD. This format presents more detailed information relevant for navigation purposes. Moving map and terrain displays underneath the navigation data together with traffic indications provides the pilot with adequate near-term situational awareness.

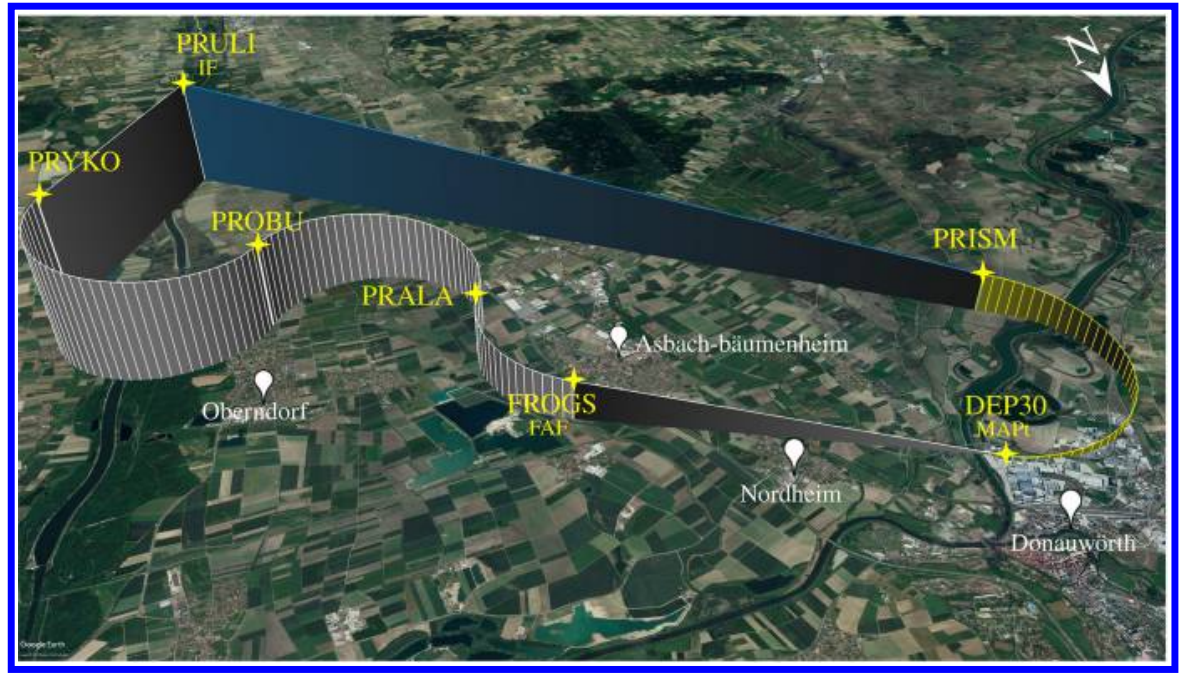

Fig. 4 Three-dimensional view of the advanced PinS approach procedure to Donauwörth heliport. 


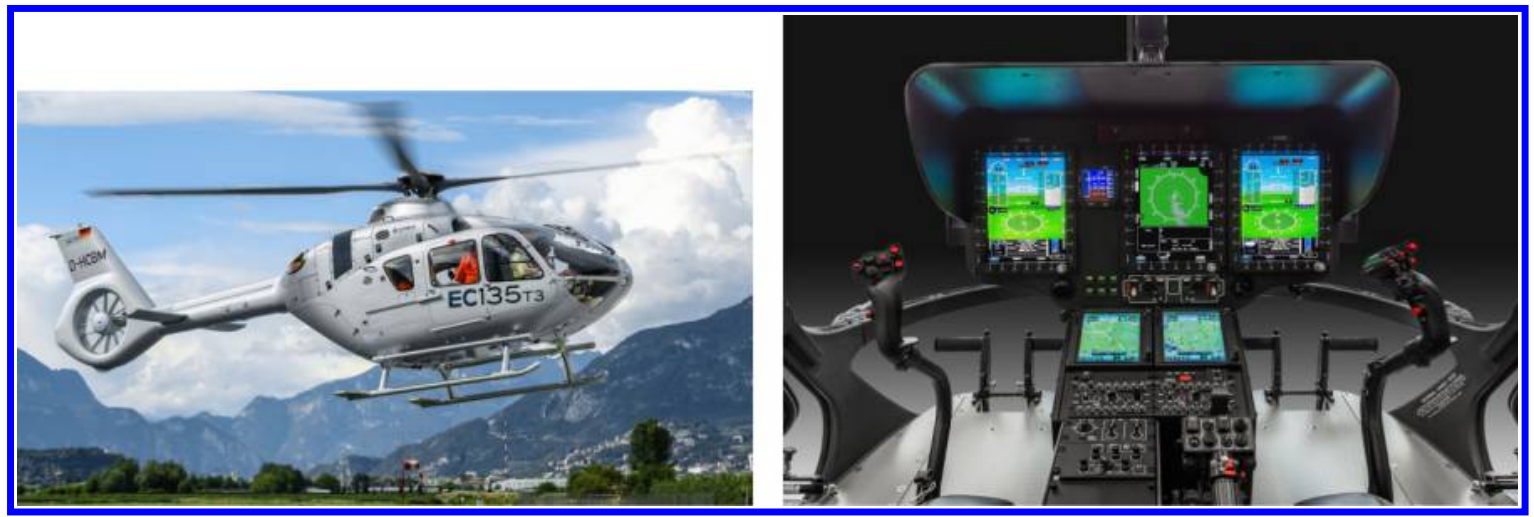

a) Representative image of H135 test aircraft

b) $\mathrm{H} 135$ and $\mathrm{H} 145$ cockpit layout

Fig. 5 Test aircraft and cockpit layout.

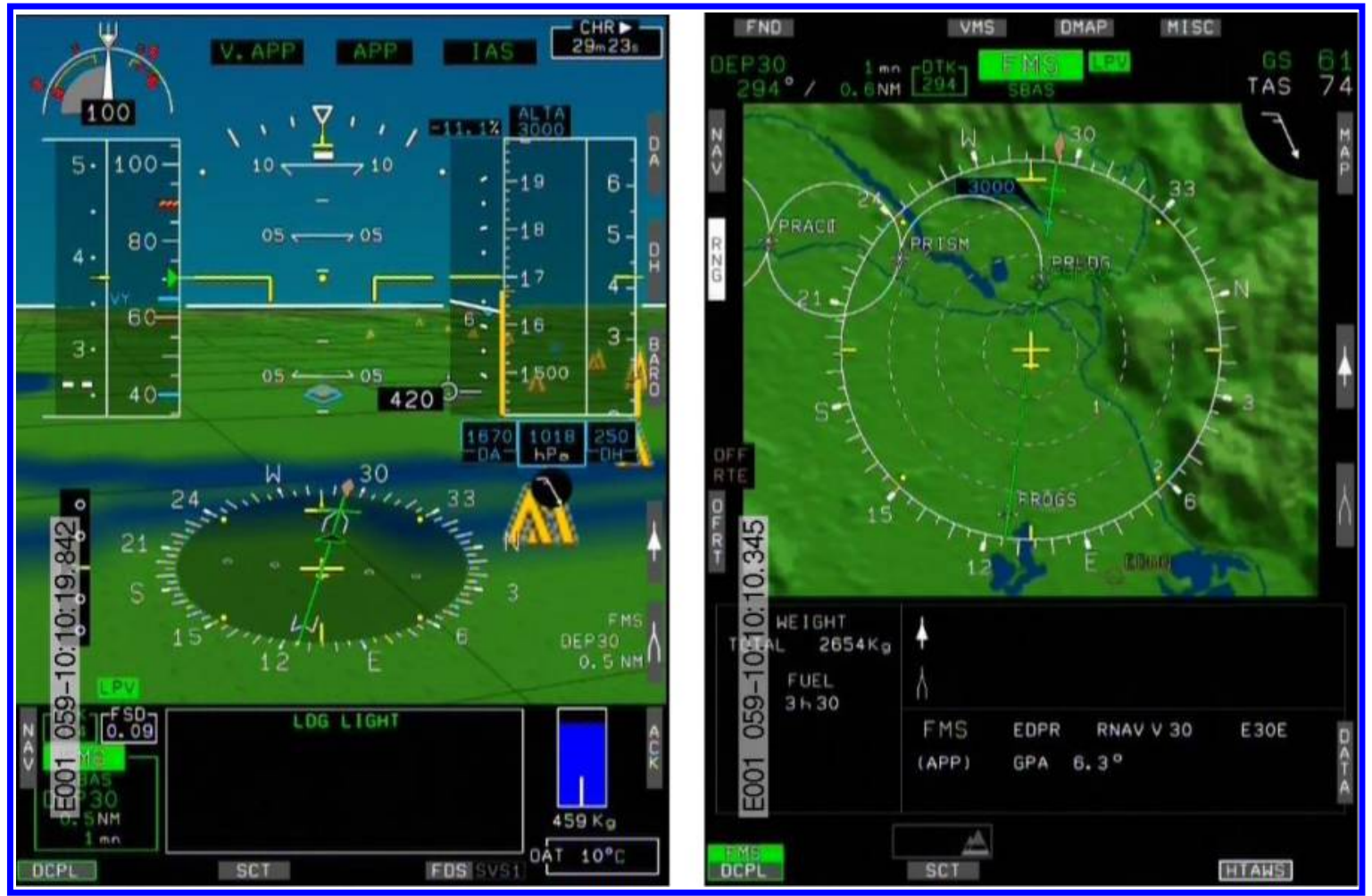

a) Primary flight display format

b) Navigation display format

Fig. 6 HELIONIX integrated avionics cockpit displays.

The procedure shown in Fig. 4 was encoded and stored in the navigation database of the FMS in the ARINC 424 format [25]. Upon activation of the approach procedure, the FMS issues steering commands to the autopilot, including transmission of the FAS data block for smooth execution of the desired lateral and vertical flight paths.

\section{Data Collection Techniques}

Two kinds of data were collected from the flight trials for postprocessing and evaluation: navigation performance and human performance. Navigation performance data were captured as part of the ARINC 429 avionic bus data record in the aircraft flight test instrumentation (FTI). They included data exchanged between FMS and MFD, as well as data from the air data computer and the attitude and heading reference system. Wind speed and wind directions are computed by the FMS by comparing airspeed data and ground velocity data. Additionally, video streams of the MFD and crew control actions in the cockpit were captured by FTI. After each flight, FTI records were downloaded onto a ground computer and time histories were extracted using company proprietary flight data processing tools. The post-processing and analyses included an evaluation of the lateral and vertical path performance in terms of the flight technical error (FTE) and the velocity vector during each phase of the approach. FTE, also referred to as the path steering error, is the ability of the flight guidance system to follow the computed flight path. The navigation system error (NSE) is the difference between true and estimated position. The path definition error (PDE) is the difference between the defined path and the desired path. The total system error (TSE) is the vector sum of FTE, PDE, and NSE, of which FTE is generally the largest contributor, and PDE is negligible and assumed to be zero. TSE is used as part of the onboard monitoring and alerting function and evaluated during flight trials to demonstrate compliance to the RNP in the different flight phases. Figure 7 depicts the computation of FTE, NSE, and TSE. Video recording of the MFD displays and crew actions as part of the FTI further eased the task of correlating post-trial PIC comments with specific instances in the flight trials.

Human performance was evaluated in terms of two key factors, namely, pilot workload, and pilot situational awareness. Pilot workload 


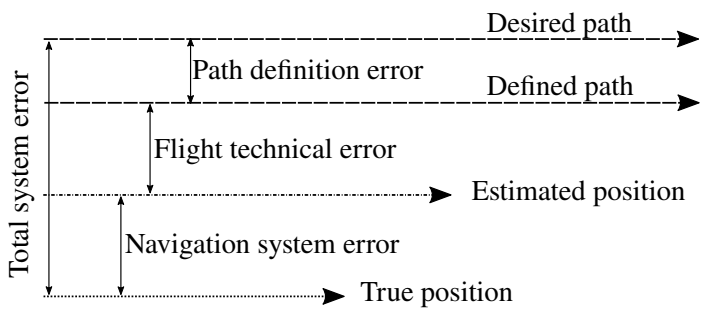

Fig. 7 Sources of cross-track errors.

measures the pilot's capacity in performing a given set of tasks. Task load index (TLX) [26], which is a standardized reference for workload evaluation in aviation and particularly in the SESAR human performance assessment process [27], was adopted for pilot workload evaluation. TLX offers a multidimensional rating procedure based on weighted average of mental demand, physical demand, temporal demand, self-performance, effort, and frustration. TLX consists of two questionnaires: the first devoted to relative weighting of the factors contributing to the workload, and the second devoted to the magnitude of each factor contributing to the workload. Workload scores were calculated post-trial using pilot responses to both questionnaires. For situational awareness evaluation, the 10-dimensional (10-D) situation rating technique (SART) was employed [28]. In a shorter version of this technique, the 10 dimensions are grouped into three dimensions covering demands on attentional resources, supply of attentional resources, and understanding of the situation. Both TLX methodology and 10-D SART techniques are nonintrusive, administered post-trial, require low training, and are completed quickly. Because each advanced PinS approach procedure was completed within $10 \mathrm{~min}$, common issues associated with these techniques such as memory degradation and poor recall were not encountered.

Each rating technique was administered using its respective paperand-pencil package. During flight briefing, the purpose and process of human performance evaluation were explained in detail to the PIC. The PIC was also asked to read the subject instructions to get familiarized with the questions and the terms used in the questionnaires. During post-flight debriefing, the filled-out questionnaires were collected for analysis. Any additional statements and oral remarks from the crew about specific flight situations were noted. These pilot statements eased the task of interpreting and validating the results of the subjective analyses.

\section{Experimental Results}

Flight trials were performed in a staggered manner between November 2018 and March 2019 depending on weather conditions. Three experimental test pilots in the age group 40-60 years participated, each holding IFR rating with an average of 5000 flight hours. In all, 6 flight hours were clocked including practice sessions for familiarization.

IMC conditions were simulated for the PIC such that out-ofcockpit visibility was restricted by a dark film on the pilot's visor. The PIC was thereby forced to focus on cockpit instruments that also included traffic advisory system indications. However, for safety purposes in experimental flight, an FTE accompanied each PIC to perform tasks including actively looking outside for VFR traffic, terrain, and obstacles. The FTE also assisted in setting up the

Table 3 Summary of environmental conditions during flight tests

\begin{tabular}{|c|c|c|c|c|c|}
\hline $\begin{array}{l}\text { Pilot } \\
\text { ID }\end{array}$ & Flight date & $\begin{array}{l}\text { Number of } \\
\text { approaches }\end{array}$ & OAT & $\begin{array}{l}\text { Wind on } \\
\text { ground }\end{array}$ & Clouds \\
\hline A1 & 30.11 .2018 & 3 & $3^{\circ}$ & $3 \mathrm{kts} / 90^{\circ}$ & $\begin{array}{c}1000-2000 \mathrm{ft} \\
\text { AGL }\end{array}$ \\
\hline A2 & 28.02.2019 & 2 & $11^{\circ}$ & $10 \mathrm{kts} / 230^{\circ}$ & Clear sky \\
\hline B & 27.02.2019 & 2 & $17^{\circ}$ & $6 \mathrm{kts} / 80^{\circ}$ & Clear sky \\
\hline $\mathrm{C}$ & 19.03.2019 & 2 & $15^{\circ}$ & $9 \mathrm{kts} / 150^{\circ}$ & Clear sky \\
\hline
\end{tabular}

approach sequences while the PIC filled out questionnaires after each approach.

In the results that follow, the three pilots are assigned identifiers (A, B , C) for uniformity and confidentiality. Pilot A performed flights on two different days, and is therefore identified as pilot A1 and pilot $\mathrm{A} 2$. The remaining PIC are identified as pilot $\mathrm{B}$ and pilot $\mathrm{C}$. Table 3 highlights the environmental conditions prevalent on flight testing days. The environmental conditions provided for a good mix between visibility and wind variations. Whereas pilot A1 encountered overcast conditions, pilots $\mathrm{A} 2$ and $\mathrm{C}$ encountered strong crosswinds and occasional turbulence at higher altitudes. Pilot B had the most benign conditions with good visibility and low wind speeds.

Two different helicopter types (Airbus H135 and H145) were used in the flight trials depending on their availability. However, the HELIONIX human-machine interface with respect to an IFR approach in both aircraft types is identical. All results are therefore commonly plotted and are comparable to each other. For conciseness and clarity, navigation performance is presented only for the flight segments between the intermediate fix (PRULI) and MAPt.

\section{A. Case 1: Constant Altitude Level-Off Approach}

In case 1 , the lateral flight path was coupled to the autopilot through the roll steering commands from the FMS. Altitude was held constant at $3000 \mathrm{ft}$ in the intermediate approach segment using the altitude hold autopilot mode. Airspeed variations were controlled manually by the pilot using the indicated airspeed (IAS) control knob to reach the target airspeed at each waypoint. Slightly before FAF, the autopilot arms the lateral and vertical approach modes. Upon reaching FAF within the glidepath capture envelope, the autopilot automatically couples the lateral and vertical approach modes and brings the helicopter to the LPV decision height.

The lateral FTE is plotted in Fig. 8a. It shows that the cross-track error remained within the RNP $0.1 \mathrm{n}$ mile containment limit during all three RF legs. The vertical-track error remained close to zero as seen in Fig. 8b and the glidepath was successfully captured at FAF. The glidepath in the final approach was, however, aborted to steer clear of an imminent dense cloud layer at $2000 \mathrm{ft}$ in this trial.

The translations states for case 1 are plotted in Fig. 9. IAS plot in Fig. 9a shows the variation of airspeed with along-track distance measured from the waypoint PRULI. The first airspeed change from 100 to $90 \mathrm{kts}$ at PROBU was initiated late, whereas airspeeds at subsequent waypoints were performed in advance of reaching the waypoint. This trend is observed because the PIC had the freedom to choose the instant of airspeed changes as long as target airspeed at waypoints was respected. Thus, depending on the workload, the PIC chose to modify airspeeds either at the beginning or in the middle of each flight leg. The vertical speed plot in Fig. $9 \mathrm{~b}$ and flight path angle in Fig. 9c were found to be well regulated until FAF, followed by a transition to slightly under $800 \mathrm{ft} / \mathrm{min} \mathrm{VS}$ and fixed $6.3^{\circ} \mathrm{FPA}$, respectively, in the FAS until MAPt.

Case 1 was flown by pilot A1 and rated very easy to fly during postflight briefing. It was therefore decided to not repeat case 1 in the subsequent flight trials with the remaining test pilots and to focus on cases 2 and 3, which were expected to induce higher workload.

\section{B. Case 2: Continuous Descent Approach Using Flight Path Angle Mode}

In case 2, the lateral flight path was coupled to the autopilot through the roll steering commands from the FMS, whereas altitude variations were controlled by the PIC using the FPA autopilot mode. The PIC monitored deviations between the current and required waypoint altitudes and adapted the nominal FPA as required. With regard to the vertical path, only two hard constraints were imposed on the PIC: 1$)$ to keep altitude errors within $\pm 300 \mathrm{ft}$ of the target altitudes, and 2) to capture the glidepath envelope at FAF. Achieving target waypoint altitudes was imposed as a soft constraint. Airspeed variations were controlled manually by the PIC using the IAS control knob to reach the target airspeed at each waypoint.

All four approaches for case 2 are plotted in Figs. 10 and 11. As shown earlier in Table $\underline{3}$, one flight (pilot A2, magenta) experienced 


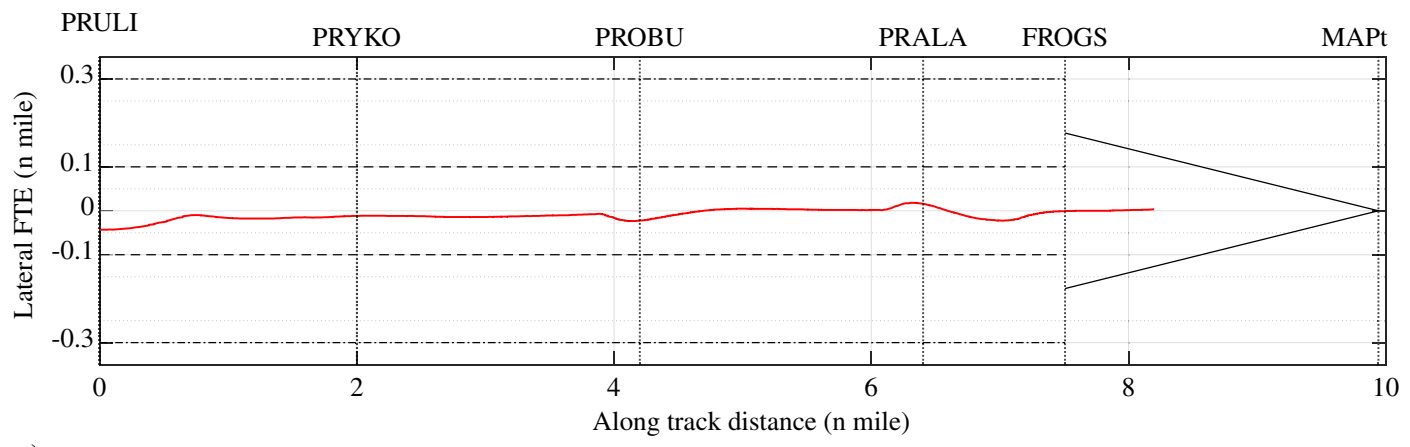

a)

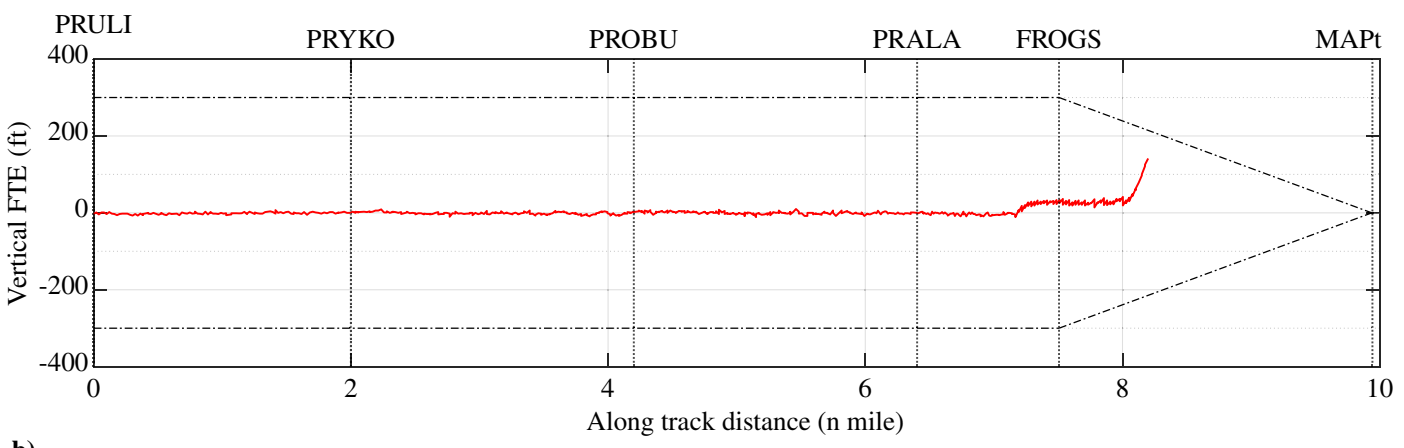

b)

Fig. 8 Flight path steering errors for case 1 (- - RNP 0.3, - - RNP 0.1, - RNP APCH angular splay, PIC: — A1).

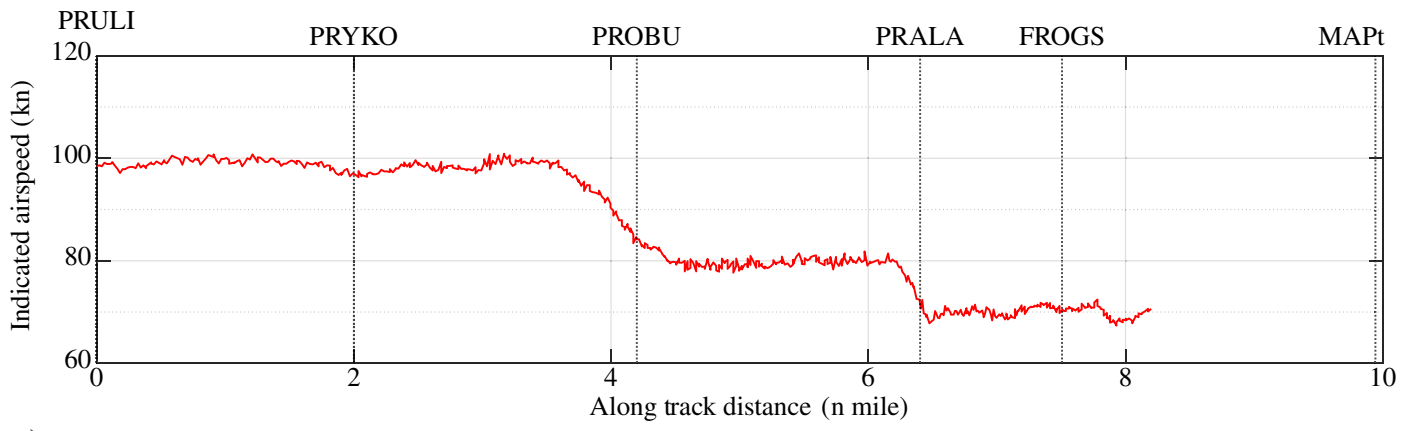

a)

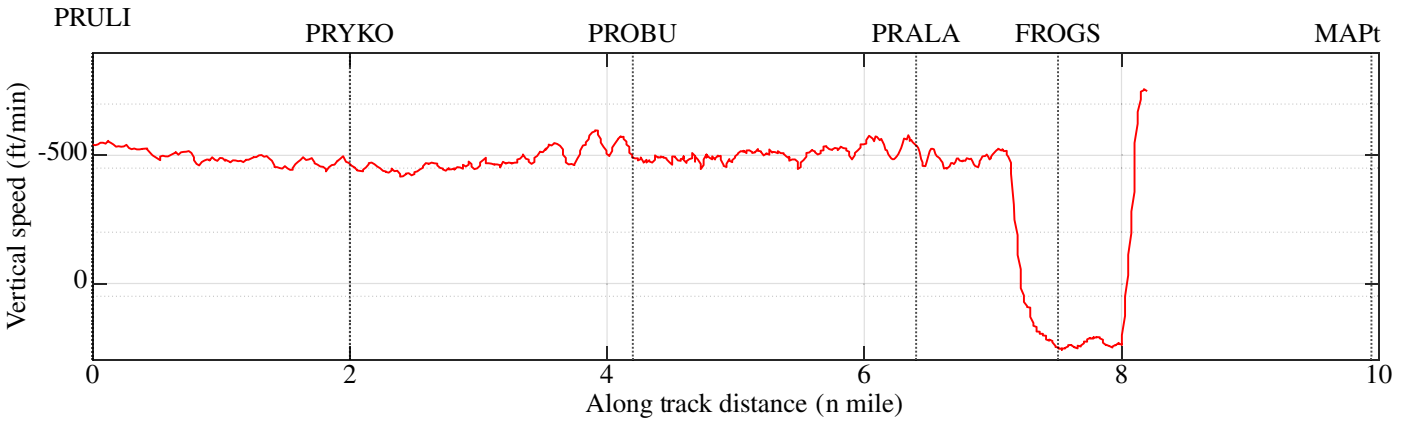

b)

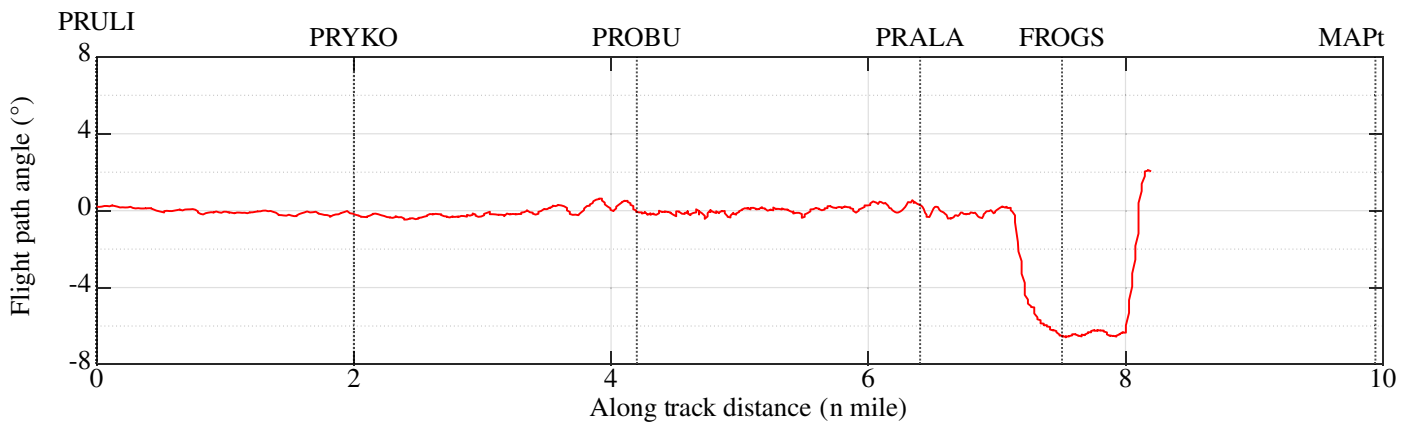

c)

Fig. 9 Translational rates for case 1 (PIC: - A1). 


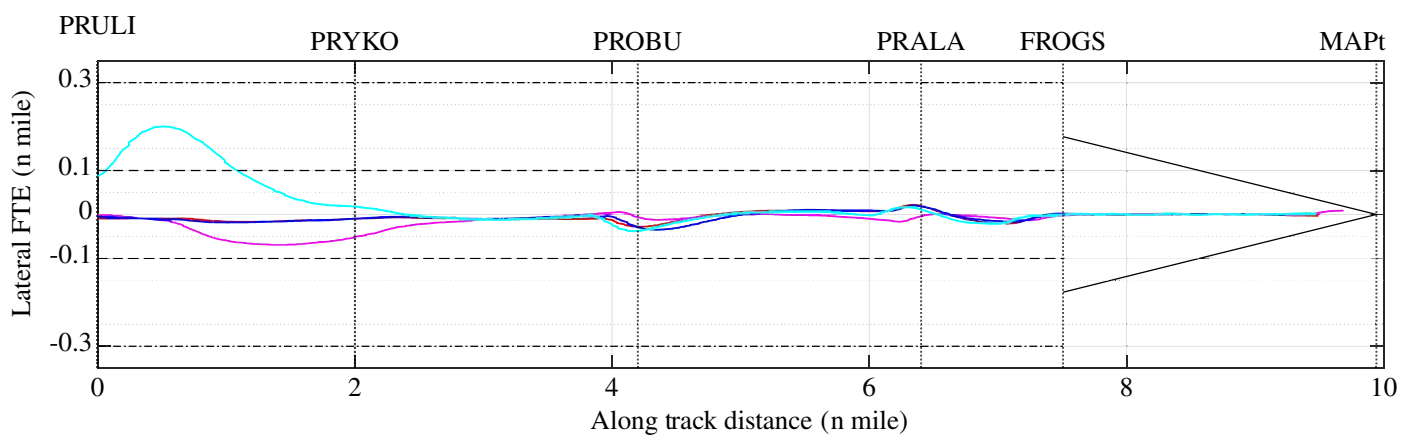

a)

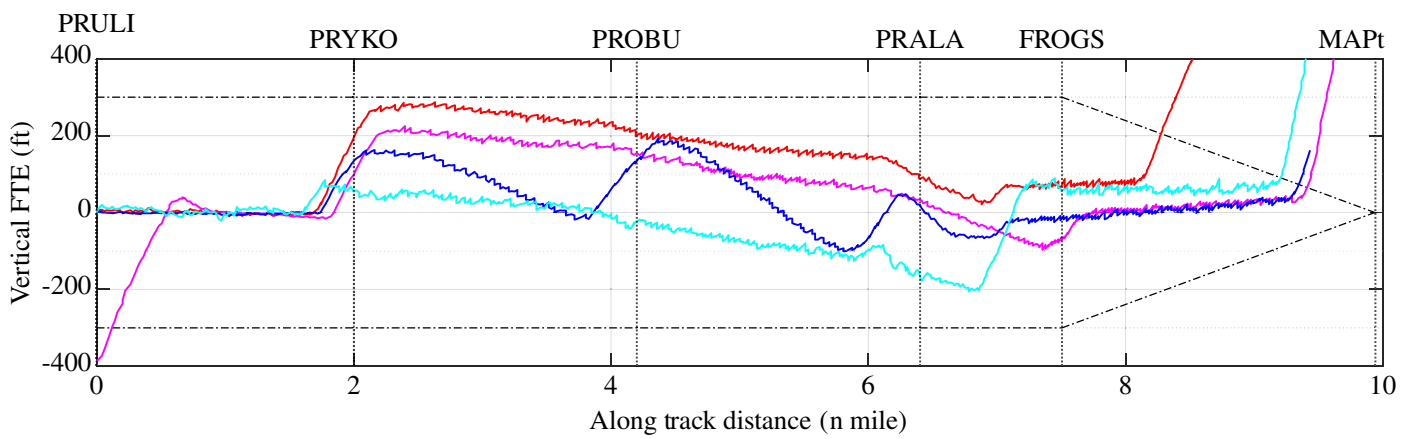

b)

Fig. 10 Flight path steering errors for case 2 (- - RNP 0.3, - - RNP 0.1, — RNP APCH angular splay, PIC: - A1, - A2, - B, - C).

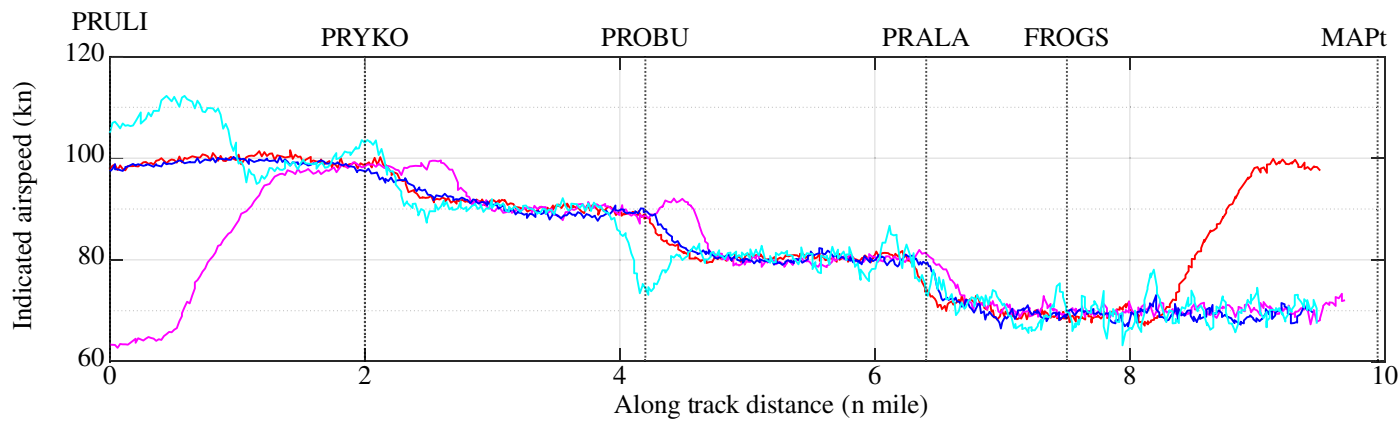

a)

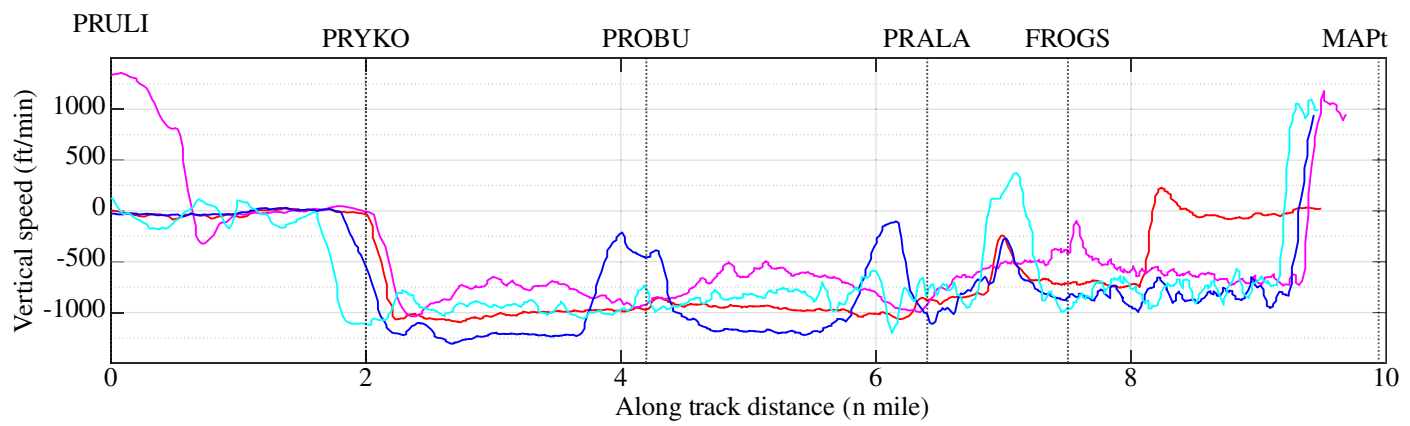

b)

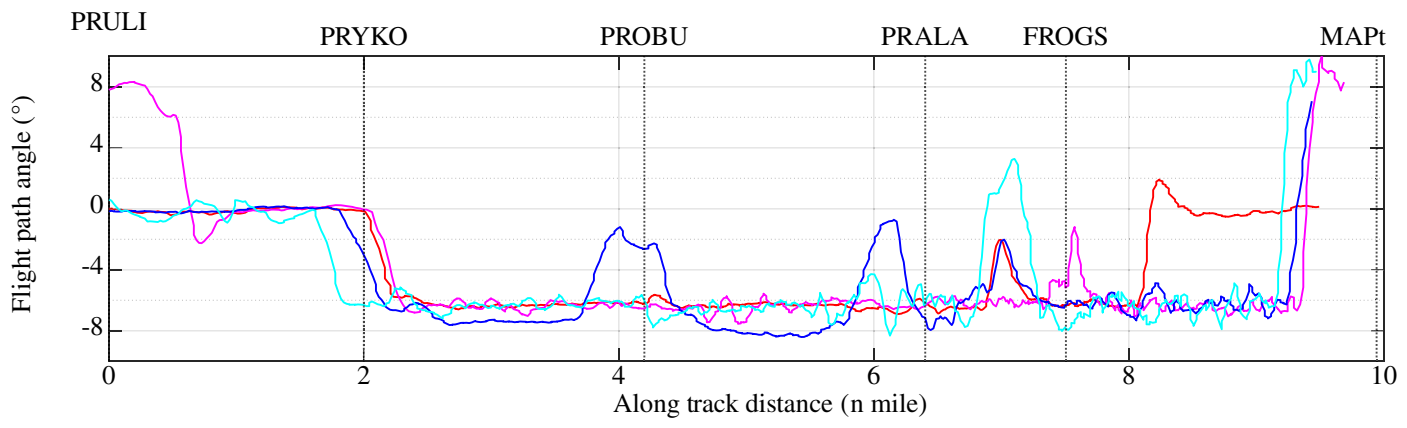

c)

Fig. 11 Translational rates for case 2 (PIC: $-\mathbf{A 1},-\mathbf{A 2},-\mathbf{B},-\mathrm{C}$ ). 
very strong winds up to $40 \mathrm{kts}$, including crosswinds during RF legs. However, the lateral flight technical error plot in Fig. 10a shows that the cross-track error during RF legs was within the $\overline{\mathrm{RNP}} 0.1 \mathrm{n}$ mile containment limit. The glidepath envelope was successfully captured by all pilots and the subsequent cross-track error was maintained within the lateral angular splay. The vertical flight technical error plot in Fig. 10b suggests that smooth, continuous descents were executed from P $\overline{R Y K O}$ to FROGS within the corridor of $\pm 300 \mathrm{ft}$. The vertical flight technical error at FAF was low and remained well within the vertical angular splay limits in the FAS.

As seen in Fig. 11a, the target airspeeds at waypoints were achieved. In Fig. 11b, it can be seen that the vertical speed profiles differed significantly to maintain the same nominal FPA of $6.3^{\circ}$. Deviations from this nominal FPA value were minimal, as observed in Fig. 11c. However, the FPA profile of pilot B (blue) in Fig. 11c differed from the other pilots because pilot B could also satisfy the soft constraint of target waypoint altitudes, as compared with other pilots that focused primarily on the hard constraints of $\pm 300 \mathrm{ft}$ altitude thresholds and glidepath capture at $3000 \mathrm{ft}$ at FAF. This action forced the autopilot to level-off at the target altitude, whereas the other pilots maintained a fixed-FPA during the complete approach. Thus, pilot B followed step-down fixes, whereas the other pilots followed a continuous descent to meet the same terminal objective. It can be further observed in Fig. 11c that all pilots sought to adapt FPA rather vigorously in the last $\mathrm{RF}$ leg before FAF in order to satisfy the hard constraint of final glidepath capture at FAF. At flight debrief, pilots recalled time pressure in this last terminal segment while preparing for the glidepath capture and simultaneously attempting to obtain external visual cues of the helipad. It was therefore recommended to include a short level-off segment before FAF to ease this pressure.

\section{Case 3: Continuous Descent Approach Using Vertical Speed Mode}

In case 3 , the lateral flight path was coupled to the FMS roll steering commands, as before. However, in this case altitude variations were controlled by the PIC using the VS autopilot mode. To satisfy both hard constraints (altitude limits and glidepath capture), the PICs monitored the deviations between the current and target waypoint altitudes as well as the required altitude at FAF, and then adapted VS accordingly. It was expected that the pilot would need to continuously adapt the nominal VS of $800 \mathrm{ft} / \mathrm{min}$ due to wind variations. IAS was controlled manually by the pilot using the IAS knob to reach target airspeeds at each waypoint.

As seen in Fig. 12a, the lateral flight technical error is found to lie within the RNP $0.1 \overline{\mathrm{nm}}$ containment limits for all the runs. An anomaly can be noticed in the magenta plot, in which the PIC A1 was required to turn around and re-initiate the approach due to an imminent VFR aircraft crossing the flight path. However, after returning to the intended flight path, the remainder of the procedure was flown within the RNP $0.1 \mathrm{~nm}$ containment limit. At FAF, the glidepath envelope was successfully captured by all pilots and the subsequent cross-track error was within the lateral angular splay. The vertical flight technical error in Fig. $12 \mathrm{~b}$ shows greater divergence from the reference altitudes as compared with case 2 with FPA. Figure $12 \mathrm{~b}$ also shows altitude excursions by PICs A1 (red) and C (cyan) from the $\pm 300 \mathrm{ft}$ threshold. This behavior can be attributed to the need for continuous adaptation of the nominal VS, particularly during strong headwinds or tailwinds. Nevertheless, all pilots were successful at capturing the glidepath envelope at the final approach fix.

The nominal $800 \mathrm{ft} / \mathrm{min}$ VS reference could hardly be met, as seen in Fig. 13b. The corresponding FPA profile in Fig. 13c shows FPA variations anywhere between 0 and $8^{\circ}$. Despite the unsatisfactory vertical profile, the target airspeeds at waypoints, however, were accurately tracked, as seen in Fig. 13a.

\section{Evaluation of Pilot Workload}

The results of pilot workload using TLX are presented in Fig. 14. For comparative assessment, pilot responses to all TLX questionnaires in Fig. 14 are grouped per case $(1,2,3)$. The first part of the questionnaire concerned the relative weight of the task factors contributing to workload. Each pilot was asked to answer the first part only once in each complete flight because each of the three cases of PinS approach was considered a different version of the same inherent task. The weight per task factor $\left(w_{i}\right)$ was calculated by counting the number of instances that each factor is selected in the pairwise comparison sheet, and then divided by 15 , the total count [26]. The mean weights and standard deviations for the five different task factors for all pilots are plotted in Fig. 14a. It indicates that pilots assigned the highest weight to the performance factor that assessed success/failure in accomplishing the advanced PinS approach procedure. This is followed by effort, mental

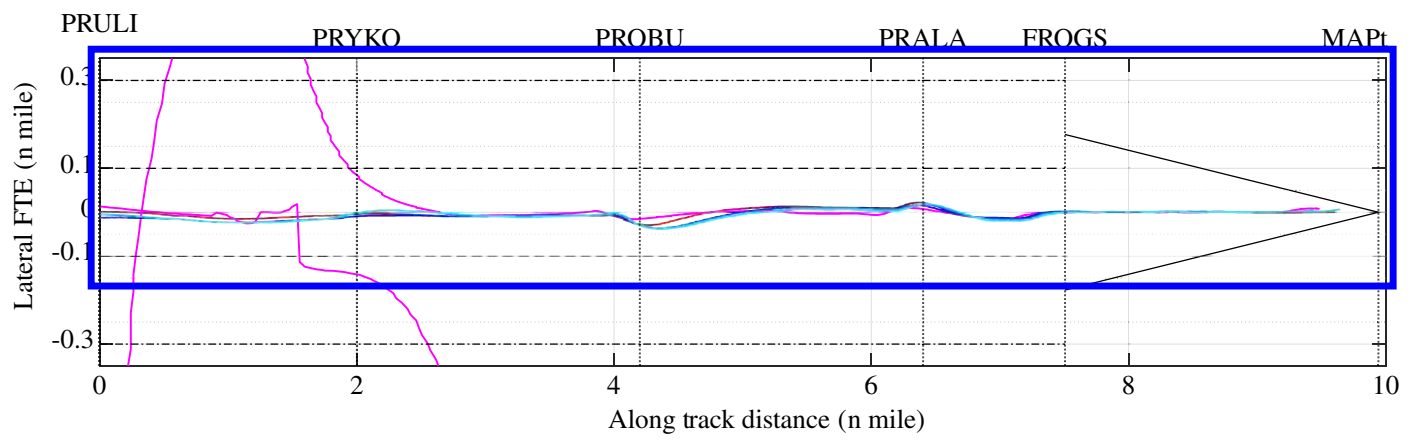

a)

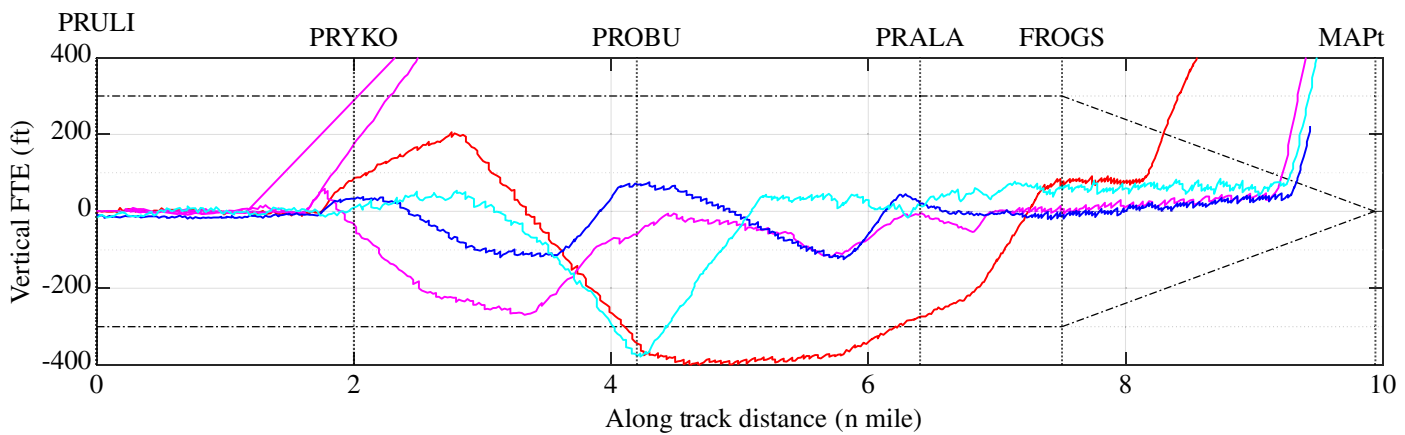

b)

Fig. 12 Flight path steering errors for case 3 (- - RNP 0.3, - - RNP 0.1, - RNP APCH angular splay, PIC: - A1, — A2, — B, - C). 


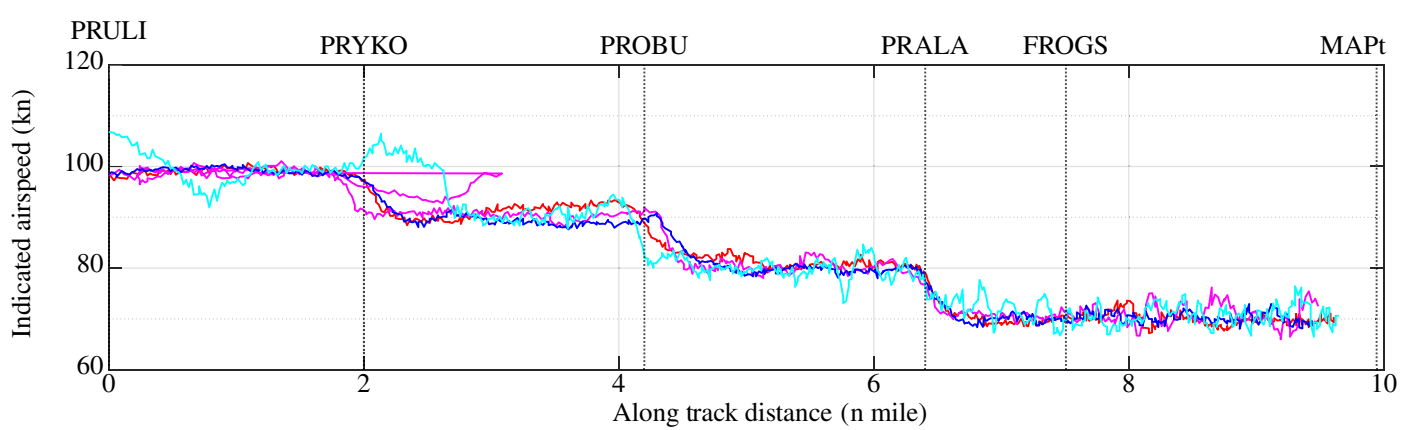

a)

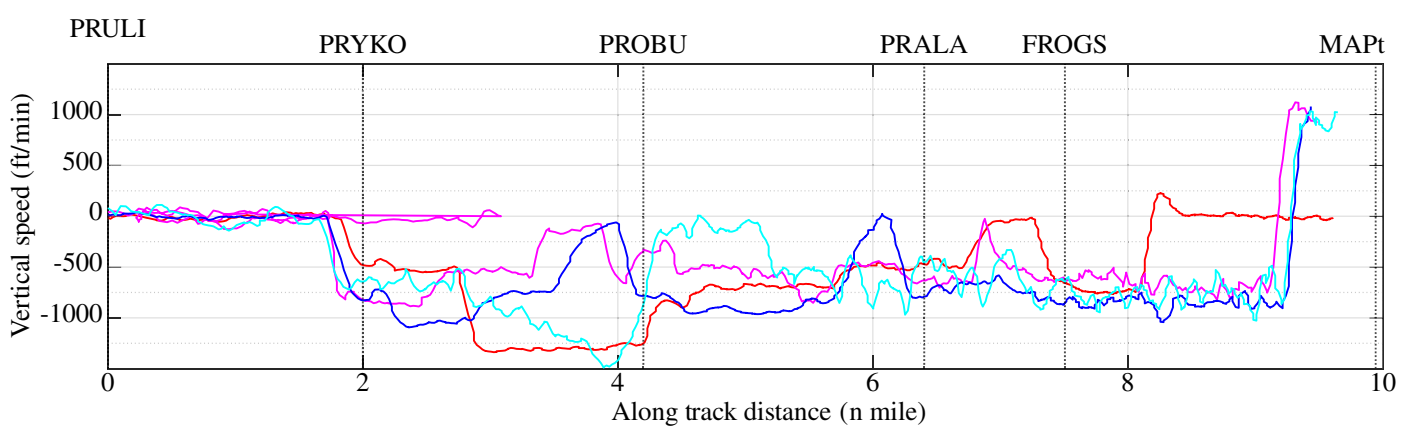

b)

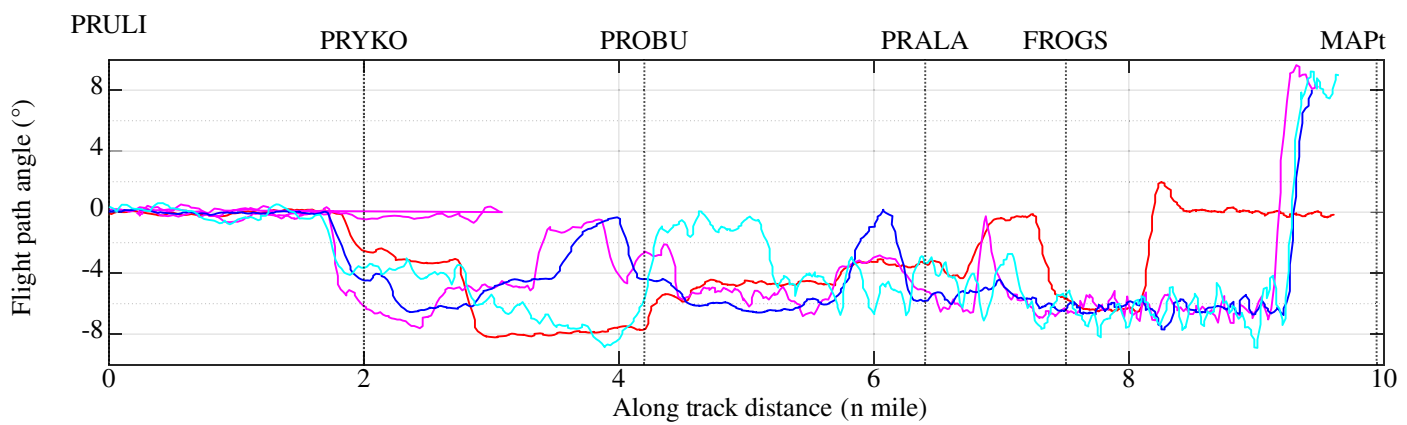

c)

Fig. 13 Translational rates for case 3 (PIC: $-\mathbf{A 1},-\mathbf{A 2},-\mathbf{B},-\mathrm{C}$ ).

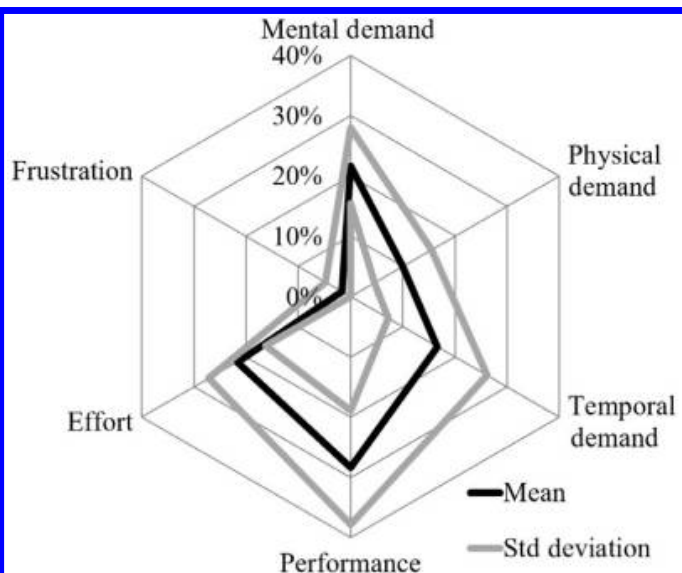

a) Mean weights per task factor

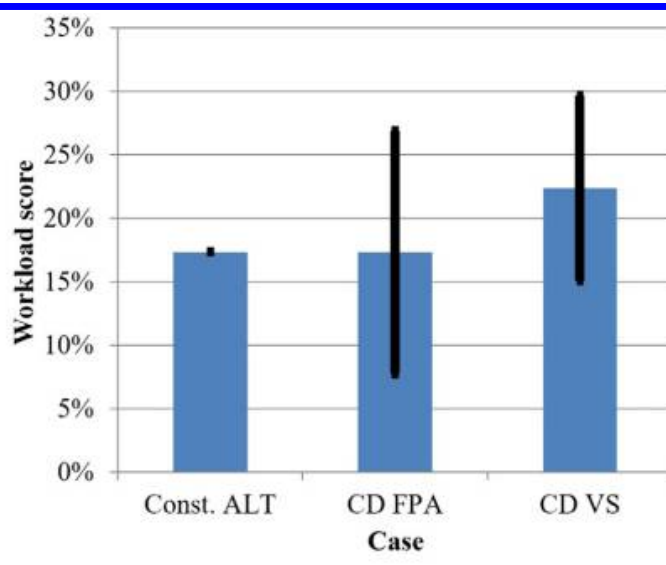

b) Mean workload score per case

Fig. 14 Pilot workload metrics using TLX methodology.

demand, and temporal demand in descending order. Physical demand and frustration received the lowest rating. A low rating for physical demand can be attributed to the use of a four-axis autopilot that required limited physical intervention by pilots during the complete approach procedure. A low rating for frustration can be attributed to the fact that all pilots had IFR ratings and were familiar with the avionics and cockpit setup. Therefore, the level of insecurity, irritation, and stress was extremely low. Overall, in terms of the contribution to workload, pilots' interaction with the task (performance, effort) was found to be marginally higher than the contribution of the demands imposed on the pilots (mental, physical, temporal demands).

Workload scores are computed as $(1 / 15) \sum_{i=1}^{5} w_{i} r_{i}$, where $r_{i}$ is the rating assigned to the $i$ th task factor. The workload score lies in the interval $[0,100] \%$, where $100 \%$ indicates the maximum amount of 
attention and efforts required to perform the task. Figure $14 \mathrm{~b}$ plots the mean workload score and standard deviations for all pilots per case. Case 1 imposes a mean workload of $17 \%$. The mean workload for case 2 and case 3 are 17 and 22\%, respectively. Assessing these values in light of the pilots' statements during flight debrief, it can be stated that the perceived workload in case 1 is low partly because of the absence of vertical maneuvers in the intermediate approach phases. However, as case 1 was flown just once with one pilot, the evidence limits a conclusive comparison with cases 2 and 3 . Comparing the mean and standard deviations for cases 2 and 3, it can be stated that, for these three pilots, case 3 imposed a higher workload due to more frequent pilot actions in adapting vertical speed than adapting flight path angle. This result also reflects pilots' opinion that descent profile using flight path angle mode, which is Earth referenced, is more intuitive and easy to fly than the same with a vertical speed mode, which is local referenced. Overall, it can be stated with confidence that all three pilots perceived themselves to have had sufficient spare capacity to cope with any anomalies and abnormal conditions that may have occurred during the advanced PinS approach procedure, such as GNSS degradations or system failures. However, due to a limited number of participants and trials, a conclusion with statistical significance cannot be established.

\section{E. Evaluation of Pilot Situational Awareness}

Pilot responses to the 10-D SART questionnaire were compiled and a composite situational awareness score was computed as $\mathrm{SA}=U-(D-S)$, where $U$ is the weighted sum of understanding, $D$ is the weighted sum of demand, and $S$ is the weighted sum of supply. The cumulative score lies in the domain $\mathrm{SA}=[-1,2]$ to indicate the lowest and highest levels of situational awareness, respectively. The mean values and standard deviations of $U, D$, and $S$ are plotted in Fig. 15a. It shows that the attentional demand is significantly lower in all cases than the attentional supply. The demand for the single flight by pilot A1 in case 1 is zero and the level of understanding is very high. This confirms the pilot statement that case 1 was easy to execute to the extent of being dull and monotonous. This can be attributed to the fact that automatic lateral flight path coupling and altitude hold mode in the intermediate approach segment, followed by 3-D coupling in the final approach, meant that pilot actions were only required for airspeed control, whereas all other parameters were being monitoring on the MFD. In contrast, cases 2 and 3 required active pilot intervention for both vertical flight path and airspeed. The mean situational awareness score, considering also the standard deviations, as seen in Fig. 15b, is thus very high at 1.6 for case 1 , and at 1.13 and 1.12 for cases 2 and 3 , respectively. Overall, the results suggest that the level of situational awareness of pilots was high for all cases. However, due to a limited number of participants and trials, a conclusion regarding situational awareness in advanced PinS with statistical significance cannot be established.

\section{Further Discussion}

The onboard avionics installation, including FMS, autopilot, and flight displays, which are capable of reading and executing the RF legs, were found to have contributed the most to maintaining RNP containment limits, pilot workload, and pilot situational awareness. All pilots reported carefree handling and adequate spare capacity to take on additional tasks, such as actively seeing and avoiding other aircraft, which is nontrivial in uncontrolled airspace, maintaining radio communications, and even handling potentially abnormal situations where necessary. The greatest pressure was reported just before the final approach fix to ensure glidepath capture, and during the final approach phase to acquire visual cues of the landing spot while keeping an eye on the cockpit instruments. The pilots were unanimous in their opinion that a head-up display format will significantly improve situational awareness and reduce workload in these phases.

The navigation and human performance in the present flight tests corroborates the findings of previous studies into rotorcraft IFR procedures [5,13]. As in the present case, Troller et al. [13] have reported better than RNP 0.1 in all nominal cases during extensive flight testing of a low-level rotorcraft IFR network in Switzerland. Likewise, Mangiaracina et al. [5] have demonstrated RNP 0.3 and acceptable workload for both pilots and ATC during rotorcraft flight trials in dense airspace.

The collective results also shed light on the overarching SESAR objectives in the rotorcraft context, namely, capacity, efficiency, safety, predictability, equity, and access. These objectives, however, can be evaluated only in a qualitative sense due to insufficient statistical data of the present tests for a comprehensive quantitative assessment.

In terms of capacity and efficiency, the advanced PinS procedure in Donauwörth had a rather small ground footprint while avoiding residential areas. This was made possible by smaller turn radii of $0.7 \mathrm{n}$ mile and lower speeds during the procedure as compared with fixed wing aircraft. By applying such procedures at busy airports, advanced PinS can potentially support additional throughput by allowing rotorcraft to approach and depart without interfering with fixed wing traffic and without additional infrastructural needs.

In terms of safety and predictability, flight data showed that all RF legs were flown well within the RNP containment limits in spite of strong wind conditions, which included strong crosswinds and mild tailwinds. RF legs also demonstrated tight path following by avoiding overshoot during leg transitions. It can be stated that flight safety is enhanced because the deviations from the intended flight path and proximity to obstacles are low, resulting in lower risk in the event of inadvertent IMC conditions. However, in abnormal conditions including navigation and avionic system degradations, adequate contingency procedures by operators must be put in place.

In terms of equity and access, the flight results from this demonstration study showed that it is possible to construct and operate GNSS-based advanced PinS procedures at all airports and heliports
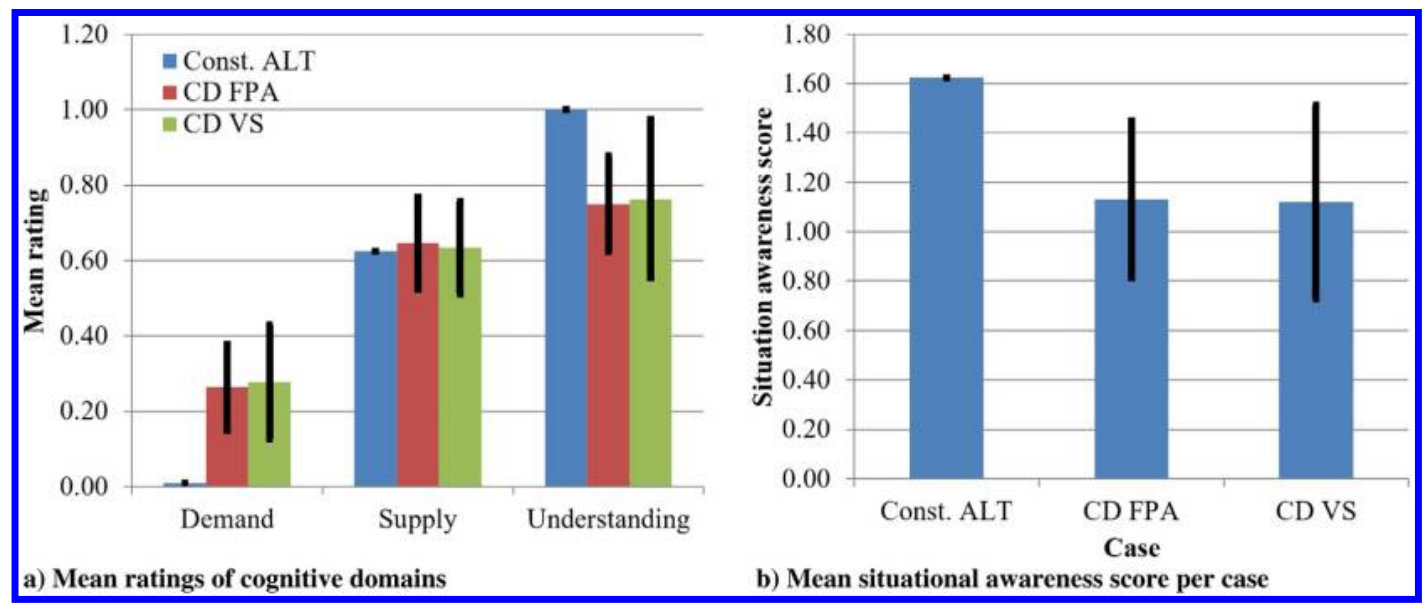

Fig. 15 Pilot situational awareness metrics using 10-D SART. 
regardless of their location, subject to the availability and integrity of GNSS and an IFR-certified avionics installation. This has the potential to enhance accessibility of rotorcraft to both dense airspace and remote, inhospitable terrain. Furthermore, PinS procedures that improve safety and predictability can also ensure equity for rotorcraft operators. PinS-based SNI procedures would allow rotorcraft to operate seamlessly in dense airspace without interfering with airline traffic. Safe and predictable path performance would increase ATC confidence, whereby ATC would be willing to offer rotorcraft operators more equitable access to dense airspace.

\section{Conclusions}

This paper has described the design and flight evaluation of helicopter-specific IFR advanced PinS procedures as part of the SESAR 2020 framework. Technical feasibility and operational readiness of advanced PinS procedures were demonstrated by means of flight testing using onboard avionics equipment, including FMS, advanced autopilot modes, and head-down flight and navigation displays.

On the basis of the flight trials, which were limited in terms of the sample size, geographical coverage, and environmental conditions, the following conclusions can be drawn:

1) Helicopters tend to fly with high slip angles particularly in crosswinds, which makes it difficult to fly curved legs with small radii. However, flight testing showed that the FMS and the chosen autopilot modes were effective, in spite of strong winds, in ensuring a lateral containment of RNP 0.1 where the requirement was RNP 0.3 , and a bounded vertical containment of $\pm 300 \mathrm{ft}$.

2) The use of advanced autopilot modes and flight monitoring functions for maintaining containment limits helped lower pilot workload, instilled confidence, and ensured carefree handling and adequate spare capacity for mission tasks. However, due to a limited number of participants, statistically relevant conclusions about workload and situational awareness cannot be established.

3) For descents in the terminal segments, the fixed flight path angle autopilot mode was more effective than the fixed vertical speed mode, mainly because it helped decouple the vertical flight path from wind conditions.

4) Pilots reported time pressure at final glidepath capture as the last RF leg terminated directly at the final approach fix. To mitigate this additional workload, a short straight level-off segment between an RF leg and the final glidepath is recommended.

5) In a qualitative sense, the results can be understood to have a positive impact of advanced PinS procedures on SESAR objectives in terms of capacity, efficiency, safety, predictability, equity, and access. The adoption of advanced PinS procedures for flight operations is expected to increase availability, enhance safety, and reduce the environmental impact of helicopters.

The head-down display formats, however, limit the pilot's ability to maintain coherent internal and external situational awareness for low-altitude operations. Further research is necessary into situational awareness enhancements during such flight phases by combining novel head-up or helmet-mounted visual augmentation aids for synthetic vision and traffic indications, and advanced autopilot and flight monitoring functions.

The point-in-space procedure concept, which has been tailored to the low-speed and low-altitude maneuvering characteristics of rotorcraft, also holds promise to facilitate safe aerial mobility in dense, urban airspace. In this regard, the results of the present work are also important to the efforts focused on future urban air mobility operations.

\section{Acknowledgments}

This project has received funding from the SESAR Joint Undertaking under the European Union's Horizon 2020 research and innovation program under grant agreement number 731864 . Thanks are due to the experimental test pilots Lionel Arlen, Raymond Laporte, and Didier Delsalle, Program Manager Thorsten Koenemann, and ATM senior expert Isabel Del Pozo. The valuable comments of Thomas Dautermann on an earlier version of the manuscript are gratefully acknowledged.

\section{References}

[1] European Helicopter Safety Team, "Analysis of 2006-2010 European Helicopter Accidents," European Aviation Safety Agency, Cologne, Germany, Aug. 2015, https://www.easa.europa.eu/sites/default/files/dfu/ EHEST_Safety-Analysis_Report-2010.pdf [accessed is 11 Dec. 2020].

[2] Netherlands Aerospace Centre, "Helicopter Flight in a Degraded Visual Environment," EASA.2011.02, European Aviation Safety Agency, Cologne, Germany, May 2013.

[3] Crognale, M. A., and Krebs, W. K., "Performance of Helicopter Pilots During Inadvertent Flight Into Instrument Meteorological Conditions," International Journal of Aviation Psychology, Vol. 21, No. 3, 2011, pp. 235-253. https://doi.org/10.1080/10508414.2011.582443

[4] "Performance-Based Navigation Manual," Doc. 9613, International Civil Aviation Organization, Montreal, 2013.

[5] Mangiaracina, F., Marhic, R., Ceretto, E., LeTallec, C., Negro, G., Lindgren, J., and Mouron, S., "SESAR Project Number 04.10 — Final Project Report," Single European Sky Air Traffic Management Research SESAR Joint Undertaking, Rept. PJ 04.10 Ed. 00.01.01, Brussels, Belgium, Dec. 2015.

[6] Hilbert, M., "Simultaneous Non Interfering (SNI) Operations, FAA Research, Development, and Implementation Efforts," Aerospace Technology Conference and Exposition, SAE TP 2005-01-3169, Oct. 2005. https://doi.org/10.4271/2005-01-3169.

[7] Visser, H., Pavel, M., and Tang, S., "Optimization of Rotorcraft Simultaneous Noninterfering Noise Abatement Approach Procedures," Journal of Aircraft, Vol. 46, No. 6, 2009, pp. 2156-2161. https://doi.org/10.2514/1.39763

[8] Rollet, P., Authesserre, M., and Sandri, F., "Flight Testing of Rotorcraft IFR Steep Approaches Using SBAS and GBAS Guidance," American Helicopter Society 64th Annual Forum, Vertical Flight Soc., Fairfax, VA, 2008.

[9] Haverdings, H., "Evaluation of a Steep Curved Rotorcraft IFR Procedure in a Helicopter-ATC Integrated Simulation Test," 34th European Rotorcraft Forum, Royal Aeronautical Soc., London, 2008.

[10] Lüken, T., Groll, E., Antrack, F., and Korn, B., "Helicopter IFR Steep and Curved Approaches Using SBAS Guidance," 34th European Rotorcraft Forum, Royal Aeronautical Soc., London, 2008.

[11] Guntzer, F., Gareton, V., Gervais, M., and Rollet, P., "Development and Testing of Optimized Instrument Flight Rules Noise Abatement Procedures on EC155," American Helicopter Society 70th Annual Forum, Vertical Flight Soc., Fairfax, VA, 2014.

[12] Moralez, E., Braddom, S., Grunwald, A., and Hovev-Rottem, M., "InFlight Evaluation of Forward-Looking Integrated Symbology for 4-D Reroutable Helicopter Approach to Blind Landing," AIAA Guidance, Navigation, and Control Conference and Exhibit, AIAA Paper 20116685, Aug. 2011.

https://doi.org/10.2514/6.2011-6685

[13] Troller, M., Scaramuzza, M., Wipf, H., Nyffenegger, M., and Leibundgut, H., "Flight Performance Investigations of Enhanced Rotorcraft Operations in Mountainous Areas-Towards a More Ambitious RNP Performance," Proceedings of the 29th International Technical Meeting of the Satellite Division of the Institute of Navigation, Inst. of Navigation, Manassas, VA, 2016, pp. 3660-3668.

https://doi.org/10.33012/2016.14813

[14] Sahin, O., Turgut, E. T., Aslaner, S., and Usanmaz, O., "Fuel and Carbon Dioxide Emission Assessment for a Curved Approach Procedure," Journal of Aircraft, Vol. 56, No. 6, 2019, pp. 2108-2117. https://doi.org/10.2514/1.C035379

[15] Dautermann, T., Mollwitz, V., Többen, H. H., Altenscheidt, M., Bürgers, S., Bleeker, O., and Bock-Janning, S., "Design, Implementation and Flight Testing of Advanced RNP to SBAS LPV Approaches in Germany," Aerospace Science and Technology, Vol. 47, Dec. 2015, pp. 280-290. https://doi.org/10.1016/j.ast.2015.09.035

[16] "Annex 14-Aerodromes-Vol. II-Heliports," International Civil Aviation Organization, Montreal, 2020.

[17] Herndon, A. A., Cramer, M., and Sprong, K., "Analysis of Advanced Flight Management Systems (FMS), Flight Management Computer (FMC) Field Observations Trials, Radius-to-Fix Path Terminators," 27th IEEE/AIAA Digital Avionics Systems Conference, IEEE Publ., Piscataway, NJ, 2008, pp. 2.A.5-1-2.A.5-15. https://doi.org/10.1109/DASC.2008.4702775

[18] Zhou, J., Cafieri, S., Delahaye, D., and Sbihi, M., "Optimization-Based Design of Departure and Arrival Routes in Terminal Maneuvering Area," Journal of Guidance, Control, and Dynamics, Vol. 40, No. 11, 2017, pp. 2889-2904.

https://doi.org/10.2514/1.G002728

[19] Polishchuk, V., "Generating Arrival Routes with Radius-to-Fix Functionalities," 7th International Conference on Research in Air Transportation (ICRAT 2016), Drexel University, Philadelphia, 2016. 
[20] "Point Merge Implementation-A Quick Guide," Edition 1.2, Eurocontrol, Brussels, March 2020.

[21] "Procedures for Air Navigation Services-Aircraft OperationsConstruction of Visual and Instrument Flight Procedures,” Doc. 8168, International Civil Aviation Organization, Montreal, 2014.

[22] "Type Certificate Data Sheet for MBB BK117," EASA.R.010, European Aviation Safety Agency, Cologne, Germany, June 2020.

[23] "Type Certificate Data Sheet for EC135," EASA.R.009, European Aviation Safety Agency, Cologne, Germany, July 2019.

[24] Ockier, C., Juppet, V., and Steiner, J., "Novel Features for Aircraft-Crew Interaction Provided by the Airbus Helicopters Helionix Avionics Suite," American Helicopter Society 71 st Annual Forum, Vertical Flight Soc., Fairfax, VA, 2015.

[25] Airlines Electronics Engineering Committee, "ARINC Specification 424-21-Navigation System Database," Collins Aerospace, Annapolis, MD, July 2016.
[26] Hart, S. G., and Staveland, L. E., "Development of NASA-TLX (Task Load Index): Results of Empirical and Theoretical Research," Human Mental Workload, edited by P. A. Hancock, and N. Meshkati, North Holland Press, Amsterdam, 1988, pp. 139-183. https://doi.org/10.1016/S0166-4115(08)62386-9.

[27] "SESAR Human Performance Assessment Process V1 to V3," SESAR 2020 PJ19, Single European Sky Air Traffic Management Research SESAR Joint Undertaking, Eurocontrol, April 2018.

[28] Selcon, S., and Taylor, R., "Evaluation of the Situational Awareness Rating Technique (SART) as a Tool for Aircrew Systems Design," Proceedings of the AGARD AMP Symposium on Situational Awareness in Aerospace Operations (AGARD-CP-4781), NATO Advisory Group for Aerospace Research and Development, Neuilly-sur-Seine, France, 1990, pp. 5/1-5/8.

P. J. Smith Associate Editor 